Jurnal Pemikiran Sosiologi Volume 7 No. 1, Januari-Juli 2020

\title{
Penggalangan Civic Literacy Melalui Organisasi Kemahasiswaan dan Pandangan mengenai Tantangan Demokrasi di Indonesia ${ }^{1}$
}

\author{
Yayuk Hidayah ${ }^{2}$ \\ Sapriya $^{3}$ \\ Cecep Darmawan ${ }^{4}$ \\ Elly Malihah ${ }^{5}$
}

\begin{abstract}
Abstraksi
Penelitian ini ditujukan untuk mendeskripsikan penggalangan civic literacy (literasi kewarganegaraan) di kalangan mahasiswa yang terlibat dalam organisasi kemahasiswaan. Tujuan penelitian untuk mengungkapkan pandangan mereka mengenai praktik demokrasi di Indonesia, khususnya melalui momentum Pemilu 2019. Metode penelitian menggunakan pendekatan kualitatif khususnya fenomenologi dengan pengambilan data wawancara, observasi dan dokumentasi. Hasil penelitian menunjukkan bahwa justru terdapat pandangan yang positif di kalangan mahasiswa terhadap pelaksanaan Pemilu 2019 sebagai skema rekruitmen kepemimpinan politik di Indonesia. Hasil penelitian juga menunjukkan bahwa dalam pandangan mahasiswa, tantangan demokrasi di Indonesia melalui Pemilu diuji oleh pengaruh budaya digital. Dalam konteks ini, pengetahuan responden tentang aspek literasi kewarganegaraan dan partisipasi politik mereka mengalami perubahan sebagai dampak dari meluasnya praktik budaya digital sehingga menjadi tantangan demokrasi Indonesia di masa depan.
\end{abstract}

Kata kunci: civic literacy, organisasi kemahasiswaan, partisipasi politik, tantangan demokrasi Indonesia, Pemilu 2019

\begin{abstract}
This research is aimed at describing civic literacy rasing among university students involved in student organizations. The research objective is to reveal their views on democratic practices in Indonesia, particularly through the moment of the 2019 elections. The research is conducted by a qualitative method, specifically by phenomenological approaches such as interviews, observation, and collecting documents. The result of the study shows that a positive outlook has been perceived by the students with regard to the 2019 election as a scheme of political leadership recruitment in Indonesia. The result also shows that according to the student perceptions, the challenge of the practice of democracy in Indonesia through the election voting has been contested by the impact of digital culture. Within this context, the respondents' knowledge about civic literacy and their political participation have been also affected by the upscaling digital practices, therefore it has been a future challenge for Indonesian democracy in next the future.
\end{abstract}

Keywords: civic literacy, student organizations, political participation, Indonesian democratic challenge, 2019 elections

\section{A. Latar Belakang}

Hajatan pemilihan umum (Pemilu) 2019 bagi

bangsa Indonesia merupakan pesta akbar yang tidak hanya memilih presiden dan wakil presiden tetapi juga memilih DPR, DPD, DPRD Provinsi, DPRD Kabupaten/kota. Pemilu serentak 2019 adalah hasil dari terbitnya putusan Mahkamah Konstitusi Nomor 14/PUU-XI/2013 terhadap permohonan uji materi Undang-Undang Nomor 42 Tahun 2008 tentang

\footnotetext{
1 Untuk kutipan atau sitasi artikel ini: Hidayah, Yayuk, et.al. 2020. "Penggalangan Civic Literacy Melalui Organisasi Kemahasiswaan dan Pandangan mengenai Tantangan Demokrasi di Indonesia."Jurnal Pemikiran Sosiologi Vol 7 (1): $31-46$

2 Departemen Pendidikan Kewarganegaraan, Fakultas Pendidikan Ilmu Pengetahuan Sosial, Universitas Pendidikan Indonesia. Email: yayukhidayah@upi.edu

3 Idem. Email:sapriya@upi.edu

${ }^{4}$ Idem. Email:cecepdarmawan@yahoo.com

${ }^{5}$ Idem. Email:ellyms@upi.edu
} 
Jurnal Pemikiran Sosiologi Volume 7 No.1 2020

Penggalangan Civic Literacy Melalui Organisasi Kemahasiswaan dan Pandangan mengenai Tantangan Demokrasi di Indonesia

Yayuk Hidayah, Sapriya, Cecep Darmawan, Elly Malihah

Pemilihan Presiden dan Wakil Presiden. Sebagai negara demokrasi, pemilihan umum bagi Bangsa Indonesia adalah konsekuensi logis, Meskipun di sisi lain masih ada ketidak sepakatan mengenai pelibatan masyarakat sebagai prasyarat bentuk pemerintahan yang demokratis. Namun keterlibatan individu pada sektor publik masih menjadi pertimbangan (Rapeli L, 2014). Sesuai dengan tujuan Pemilu yang termuat dalam UndangUndang Nomor 8 tahun 2012 pasal 3, Pemilu bagi bangsa Indonesia menjadi salah satu jalan dalam menentukan pemimpin yang sesuai dengan Pancasila dan Undang-Undang Negara Republik Indonesia tahun 1945.

Terdapat tiga tujuan Pemilu yaitu; 1) sebagai mekanisme pemilihan pemimpin dan sebagai alternatif kebijakan umum, 2) pemindahan konflik kepentingan, 3) sarana mobilisasi dalam proses politik (Prihatmoko, 2003). Sementara secara fungsi, pemilu berfungsi sebagai mempertahankan demokrasi di Indonesia, mencapai keadian dan kemakmuran sesuai dengan Pancasila dan tegaknya Pancasila dan UUD 1945 (Kansil \& Kansil, 2011). Setelah melalui berbagai lakon drama mengenai pelaksanaan Pemilu di Indonesia hingga akhirnya mencapai kemufakatan dalam bentuk Pemilu serentak pada tahun 2019, yang menjadi pertanyaan selanjutnya adalah bagaimana Pemilu 2019 dilaksanakan dan bagaimana dampaknya bagi tantangan demokrasi Indonesia di masa depan?

Pelaksanaan Pemilu serentak 2019 menjadi anasir bagi akademisi Pendidikan Kewarganegaraan dalam memberikan sumbangan pemikiran mengenai dinamika yang terjadi di Indonesia. Pendidikan Kewarganegaraan sebagai subjek wajib

yang diberikan hingga tingkat Perguruan Tinggi sesuai dengan yang tercantum dalam UndangUndang No 20 Tahun 2003 tentang Sistem Pendidikan Nasional pada Pasal 37 ayat (1) dan (2) mempunyai kontribusi dalam anasir Pemilu 2019. Sebagaimana kajian Pendidikan Kewarganegaraan secara umum mencakup tiga aspek yaitu civic knowledge yang mencakup pengetahuan kewarganegaraan, civic dispotition yang mencakup karakter kewarganegaraan dan civic skills yang meliputi keterampilan intelektual dan keterampilan partisipatoris.

Keterlibatan warga negara Indonesia dalam pemilu 2019 menjadi kesempatan bagi pemenuhan hak politik bagi warga negara Indonesia. Hak politik bagi warga salah satnya terwujud dalam partisipasi dengan pemberian hak pilih saat pemilihan (Fachruddin, 2006). Bagi warga Indonesia, Pada Usia 17 tahun telah mempunyai tanggung jawab politik, tidak terkecuali bagi mahasiswa yang merupakan calon pemimpin di masa depan bagi bangsa Indonesia. Mahasiswa selama berada di bangku kuliah dipertemukan dengan berbagai kehidupan yang berbeda dengan masa sebelumnya yaitu masa sekolah. Di kampus, mahasiswa akan bertemu dengan organisasi kemahasiswaan dalam berbagai bungkusan nama. Namun tetap dalam tujuan untuk mengelaborasi minat bakat mahasiswa. Keberadaan organisasi kemahasiswaan di Indonesia secara tertulis ada dalam Keputusan Menteri Pendidikan Dan Kebudayaan Republik Indonesia Nomor 155 /U/1998 Tentang Pedoman Umum Organisasi Kemahasiswaan Di Perguruan Tinggi. 
Jurnal Pemikiran Sosiologi Volume 7 No.1 2020

Penggalangan Civic Literacy Melalui Organisasi Kemahasiswaan dan Pandangan mengenai Tantangan Demokrasi di Indonesia

Yayuk Hidayah, Sapriya, Cecep Darmawan, Elly Malihah

Keterlibatan mahasiswa dalam organisasi kemahasiswaan menjadi motivasi bagi peneliti dalam menginvestigasi tantangan demokrasi Indonesia di masa depan mengingat sintesis demokrasi yang berkembang dalam wahana demokrasi. Peneliti tertarik mengkaji lebih dalam mengenai keberadaan civic literacy melalui organisasi kemahasiswaan khususnya dihadapkan pada perhelatan Pemilu serentak 2019. Rumusan masalah dalam penelitian ini adalah "bagaimana penggalangan civic literacy berlangsung melalui organisasi kemahasiswaan turut mempengaruhi pandangan mereka mengenai tantangan demokrasi Indonesia di masa depan?" Permasalahan penggalangan civic literacy melalui organisasi kemahasiswaan menjadi menarik untuk dikaji, terutama ketika dihadapkan dengan "pesta" Pemilu serentak 2019. Berdasarkan hasil penjajakan terhadap penelitian terdahulu mengenai civic literacy maupun keterlibatan mahasiswa dalam Pemilu terhimpun sebagai berikut. Pertama, penelitian tahun 2009 dengan melibatkan sekitar 134.000 dari 38 negara di seluruh Eropa, Asia, dan Amerika Latin, menghasilkan bahwa perlunya ruang untuk mendiskusikan di luar ruang kelas dalam rangka mempersiapkan warganegara yang aktif (Lin, 2014). Kajian mengenai literasi politik dan keterlibatan warga negara merekomendasikan bahwa harus diadakan ruang baru dalam meningkatkan pemahaman mengenai peran agen politik dan kegiatan yang dapat membentuk minat anak muda untuk dapat berpartisipasi atau bahkan tidak berpartisipasi (Dudley \& Gitelson, 2002).

Selanjutnya, hasil penelitian IEA (International Association for the Evaluation of
Educational Achievement) terhadap 90.000 siswa berusia 14 tahun di 28 negara menunjukkan bahwa sekolah mempunyai peran dalam mendorong keterlibatan warga dan mengajarkan keterampilan kewarganegaraan dengan memperhatikan iklim kelas, penekanan pada pentingnya Pemilu, dan budaya yang partisipatif (Torney-Purta, 2010). Penelitian lainnya mengenai hubungan pelaksanaan pendidikan moral dan sipil dalam menumbuhkan literasi kewarganegaraan dalam konteks AsiaPasifik menujukkan hasil yakni terdapat pengetahuan yang meningkat dalam kategori keterampilan demokratis, pemikiran kritis, pengetahuan sipil, toleransi dan kebajikan demokratis setelah siswa mengikuti pendidikan moral dan sipil (Leung \& Chan, 2019). Penguatan civic literacy yang dilakukan di HMP PPKn Demokratia di Dusun Binaan Mutiara Ilmu, Jebres, Surakarta menghasikan bahwa terdapat impilikasi pada penguatan ketahanan kepribadian warga negara muda (Raharjo, Armawi, \& Soerjo, 2017). Dalam bidang pembelajaran, hasil penelitian itu menunjukan bahwa diperlukan pendekatan yang berbeda dalam pembelajaran Mata Kuliah Wajib Umum di Perguruan Tinggi pada subjek Pendidikan Kewarganegaraan dan Pancasila guna menunjang penguasaan kompetensi kewarganegaraan mahasiswa (Hidayah, Yayuk, Ulfah Nufikha, Suyitno, 2019)

Berdasarkan dari hasil penelitian penelitian tersebut dapat diketahui bahwa penguatan civic literacy berkontribusi dalam menumbuhkan minat dan pengetahuan terhadap politik. Selain itu, dapat diketahui juga bahwa belum ada penelitian yang mengkaji mengenai 
Jurnal Pemikiran Sosiologi Volume 7 No.1 2020

Penggalangan Civic Literacy Melalui Organisasi Kemahasiswaan dan Pandangan mengenai Tantangan Demokrasi di Indonesia

Yayuk Hidayah, Sapriya, Cecep Darmawan, Elly Malihah

penggalangan civic literacy melalui organisasi kemahasiswaan dan pengetahuan mereka tentang literasi kewarganegaraan dan dampaknya dalam partisipasi politik sebagai tantangan demokrasi Indonesia di masa depan. Terpaut dengan tujuan Pendidikan Kewarganegaraan sebagai subjek kajian dengan kajian yang banyak membahas menenai warga negara dan penyiapan smart and good citizen. Fungsi Pendidikan Kewarganegaraan adalah sebagai usaha yang sadar secara ilmiah dan psikologis dengan dilandasi pada tujuan pendidikan nasional, agar memudahkan peserta didik dalam menginternalisasi moral Pancasila yang terwujud dalam tindakan sehari-hari (Soemantri, 2011). Dengan dasar latar belakang tersebut, peneliti terdorong untuk meneliti proses penggalangan civic literacy dengan melakukan penelitian melalui organisasi kemahasiswaan di Daerah Istimewa Yogyakarta.

\section{B. Metode Penelitian}

Metode yang digunakan adalah penelitian kualitatif dengan pendekatan fenomenologi. Peneliti menggunakan pendekatan fenomenologi karena peneliti ingin lebih leluasa dalam menangkap fenomenena penggalangan civic literacy melalui organisasi kemahasiswaan dalam tantangan demokrasi Indonesia di masa depan. Penelitian kualitatif yang peneliti lakukan mengacu pada penyajian data berupa pernyataan (kata-kata) dan bukan pada hasil statistik. Metode kualitatif merupakan penelitian yang menghasilkan data berupa pernyataan (Bogdan, 1993; Moleong, 2007). Subjek penelitian penggalangan civic literacy

melalui organisasi kemahasiswaan dalam tantangan demokrasi Indonesia di masa depan adalah 24 mahasiswa yang berasal dari jurusan yang berbeda yang terlibat dalam organisasi kemahasiswaan Badan Eksekutif Mahasiswa (BEM) di delapan (8) kampus yang berbeda di Daerah Istimewa Yogyakarta, Indonesia. Yaitu; Univesitas Gadjah Mada, Yogyakarta, Univesitas Negeri Yogayakarta, Univesitas Sanata Dharma, Yogayakarta. Univesitas Islam Negeri "Sunan Kalijaga" Yogyakarta. Universitas Atmajaya Yogyakarta, Universitas Ahamad Dahlan, Yogyakarta. Universitas Islam Indonesia, Yogyakarta. Universitas Kristen Duta Wacana Yogyakarta.

Tabel 1. Sebaran Subjek Penelitian

\begin{tabular}{|c|c|c|}
\hline Demografi & Jumlah & Total \\
\hline \multicolumn{3}{|l|}{ Gender } \\
\hline Laki-Laki & 15 & 15 \\
\hline Perempuan & 10 & 9 \\
\hline \multirow[t]{2}{*}{ Usia (tahun) } & $18-20$ & 16 \\
\hline & $21-24$ & 8 \\
\hline Tk Pendidikan & \multicolumn{2}{|l|}{ Mahasiswa S1 } \\
\hline \multirow[t]{10}{*}{ Jurusan } & Manajemen & 3 \\
\hline & Psikologi & 1 \\
\hline & $\begin{array}{l}\text { Pendidikan } \\
\text { Bahasa Inggris }\end{array}$ & 2 \\
\hline & $\begin{array}{l}\text { Pendidikan } \\
\text { Agama Islam }\end{array}$ & 1 \\
\hline & Tekhnik Kimia & 1 \\
\hline & Biologi & 2 \\
\hline & Arsitektur & 1 \\
\hline & $\begin{array}{l}\text { Pendidikan } \\
\text { Bimbingan dan } \\
\text { Konseling }\end{array}$ & 2 \\
\hline & $\begin{array}{l}\text { Pendidikan Seni } \\
\text { Tari }\end{array}$ & 1 \\
\hline & Biologi & 3 \\
\hline
\end{tabular}


Jurnal Pemikiran Sosiologi Volume 7 No.1 2020

Penggalangan Civic Literacy Melalui Organisasi Kemahasiswaan dan Pandangan mengenai Tantangan Demokrasi

Yayuk Hidayah, Sapriya, Cecep Darmawan, Elly Malihah

\begin{tabular}{|l|l|l|}
\hline \multirow{1}{*}{} & $\begin{array}{l}\text { Pendidikan } \\
\text { Ekonomi }\end{array}$ & 3 \\
\cline { 2 - 3 } & Komunikasi & 2 \\
\cline { 2 - 3 } & $\begin{array}{l}\text { Ilmu } \\
\text { Pemerintahan }\end{array}$ & 1 \\
\cline { 2 - 3 } & Teknik Industri & 1 \\
\hline $\begin{array}{l}\mid 2 \\
\text { Total } \\
\text { Partisipan }\end{array}$ & $\mathbf{2 4}$ \\
\hline
\end{tabular}

(Sumber: Data primer, diolah oleh peneliti, 2019)

Data diperoleh peneliti melalui wawancara secara tersetruktur dengan menggunakan cakupan pedoman wawancara dengan cakupan pertanyaan:

1) Bagaimanakah pendapat responden (mahasiswa) mengenai Pemilu serentak?

2) Apakah responden (mahasiswa) mengetahui isu kenegaraan terkini?

3) Bagaimanakah pendapat responden (mahasiswa) mengenai partisipasi politik era kini?

Setiap wawancara berlangsung selama 30-45 menit dan dilakukan di tempat yang berbeda sesuai dengan kesepakatan dengan informan. Sebagai kelengkapan alat wawancara, peneliti menggunakan alat rekam, dan alat tulis.

Perolehan data selanjutnya peneliti peroleh melalui observasi yang dilakukan selama bulan Maret 2019-Agustus 2019. Observasi yang peneliti lakukan adalah observasi non partisipan dengan kombinasi observasi terbuka. Sesuai dengan acuan Moleong (2007) bahwa observasi non partisipan adalah observasi yang hanya melakukan satu fungsi yaitu pengamatan, maka dalam penelitian ini peneliti hanya mengamati gejala penggalangan civic literacy melalu organisasi kemahasiswaan dalam tantangan demokrasi Indonesia di masa depan secara cermat, fokus objektif dan jujur.

Observasi terbuka yang peneliti lakukan adalah dengan berdasarkan anteseden menurut Moleong (2007), yaitu dalam observasi terbuka kehadiran peneliti diketahui subjek penelitian dan subjek penelitian memberikan kesempatan bagi peneliti untuk melakukan observasi. Observasi terbuka yang peneliti lakukan dalam penelitian penggalangan civic literacy melalui organisasi kemahasiswaan dalam tantangan demokrasi Indonesia di masa depan adalah mengadakan pengamatan pada aktivitas BEM di 8 kampus berbeda di Daerah Istimewa Yogyakarta yang berlangsung, sebelum dan sesudah Pemilu 2019. Peneliti menggunakan alat bantu berupa kamera, alat tulis guna memperoleh data yang dibutuhkan. Berikutnya peneliti memperoleh data melalui dokumentasi. Dokumetasi peneliti peroleh melalui catatan lapangan, program kerja masing-masing BEM, jurnal, artikel hasil penelitian terkini, buku dan dokumen lainnya dalam bentuk soft file atau hard file yang peneliti anggap relevan dengan permasalahan yang hendak dikaji.

Analisis data dalam penelitian ini menggunakan pendekatan Miles dan Huberman (1992) berupa reduksi data, penyajian data dan penarikan kesimpulan. Reduksi data peneliti lakukan dengan mengumpulkan peroleh keseluruhan data kemudian peneliti mengkategorkan data sesuai dengan permasalahan agar dapat memperkuat penelitian. Reduksi data merupakan proses penyederhanaan data yang muncul di lapangan (Miles \& Huberman, 1992). Setelah mereduksi data, peneliti kemudian menyajikan data dalam bentuk susunan kalimat yang selanjutnya digunakan untuk penarikan 
Jurnal Pemikiran Sosiologi Volume 7 No.1 2020

Penggalangan Civic Literacy Melalui Organisasi Kemahasiswaan dan Pandangan mengenai Tantangan Demokrasi di Indonesia

Yayuk Hidayah, Sapriya, Cecep Darmawan, Elly Malihah

kesimpulan. Validasi data yang peneliti lakukan adalah menggunakan metode trianggulasi. Metode tianggulasi dilakukan dengan membandingkan data yang peneliti peroleh dengan menggunakan metode lain yang berbeda.

\section{Kerangka Teoritik: Civic Literacy}

Pijakan teori civic literacy dalam penelitian ini berasal dari perkembangan civic literacy yang telah berkembang. Robert Putnam (1995) sebagaimana dikutip oleh Milner (2001) memberikan pengintensifan mengenai penurunan jumlah pemilih dalam pemilihan nasional di Amerika Serikat. Menurutnya, Putnam memberikan perhatian bahwa keanggotaan dalam organisasi menjadi indikator keterlibatan masyarakat (Milner H., 2001). Secara singkat, argumen Putnam (1995) mengenai modal sosial untuk partisipasi politik inilah yang digunakan sebagai kebanyakan basis teoritik untuk kajian tentang civic literacy.

Civic literacy adalah seperangkat komponen keterampilan kewarganegaraan yang terdiri dari pengetahuan kewarganegaraan (civic knowledge), watak kewarganegaraan (civic dispotition), keterampilan intelektual (civic skills) baik keterampilan partisipatoris dan keterampilan intelektual. Menurut Suryadi (2010), civic literacy adalah pengetahuan dan kemampuan warga negara dalam mengatasi masalah sosial, politik dan kenegaraan. Civic literacy mengarah pada pembentukan warga negara yang mampu mengatasi permasalahan berbangsa dan bernegara (Raharjo et al., 2017). Dalam berbagai kajian mengenai civic 
Jurnal Pemikiran Sosiologi Volume 7 No.1 2020

Penggalangan Civic Literacy Melalui Organisasi Kemahasiswaan dan Pandangan mengenai Tantangan Demokrasi di Indonesia

Yayuk Hidayah, Sapriya, Cecep Darmawan, Elly Malihah

Gambar 1: Hasil Analisis Kualitatif Literatur tentang civic literacy

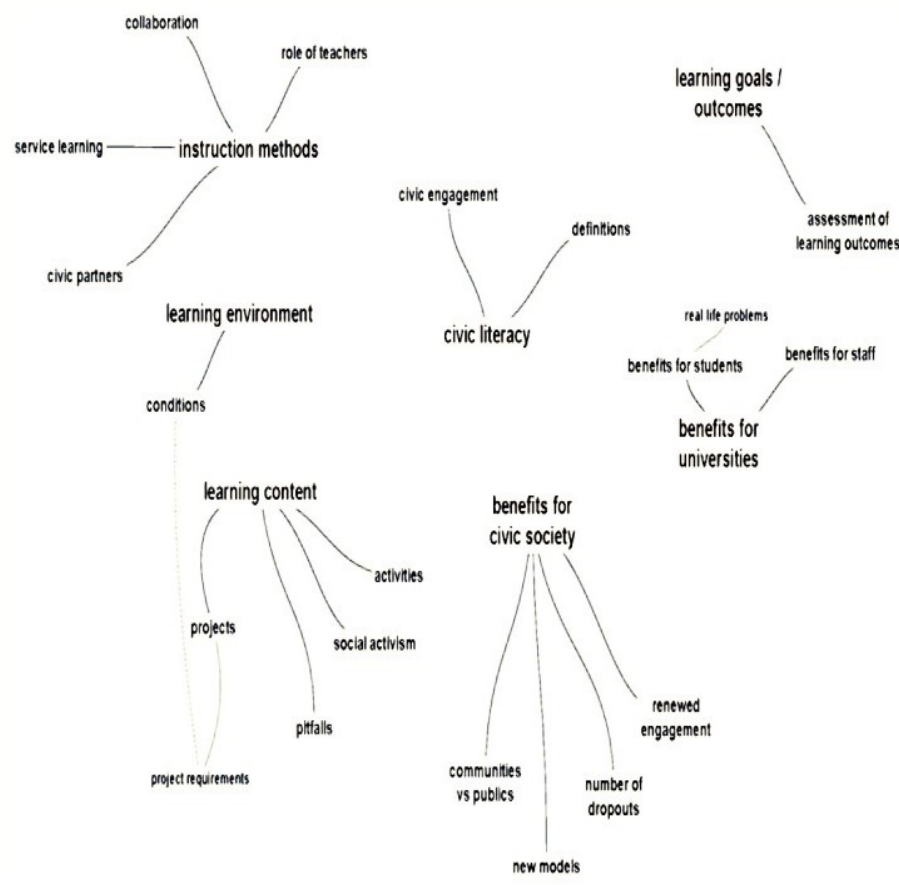

(Sumber: Van Helvoort J, 2019).

Berdasarkan gambar 1 dapat diketahui bahwa dalam memberikan gambaran yang utuh mengenai civic literacy terdapat banyak ranting. Civic literacy adalah bentuk kesatuan dalam pemusatan permasalahan yang menuntut adanya kesempurnaan kompetensi bagi warga negara dalam mengatasi permasalahan. Dalam demokrasi di Amerika Serikat, civic literacy termisikan dalam semangat ekonomi serta komunitas global untuk menumbuhkan warga negara yang berpengetahuan, berpikiran terbuka, dan bertanggung jawab secara sosial untuk kebaikan bersama (Pollack S.S., 2015).

\section{Temuan dan Analisis: Partisipasi Politik Melalui Pemilu 2019 dan Tantangan Demokrasi di Era Digital}

Pada hasil dan pembahasan penelitian ini, peneliti mengkolaborasikan temuan kemudian membahasnya secara langsung. Sesuai dengan rumusan masalah bagaimana penggalangan civic literacy melalui organisasi kemahasiswaan dalam menghadapi tantangan demokrasi Indonesia di masa depan. Peneliti menganalisis secara mendalam dan jelas temuan di lapangan yang kemudian bermanfaat bagi penarikan kesimpulan yang sesuai dengan hasil dan pembahasan.

Mahasiswa yang terlibat dalam BEM memberikan berbagai pendapat mengenai Pemilu serentak 2019, sebagaimana dalam kutipan wawancara dengan RADP mahasiswa Jurusan Manajemen yang terlibat dalam BEM Universitas Kristen Duta Wacana Yogyakarta berikut ini.

Pewawancara: Bagaimanakah pendapat anda mengenai Pemilu serentak 2019?

RADP: Pemilu serentak tentu saja merupakan bagian baru dalam perjalan demokrasi kita (Indonesia) Pemilu serentak yang katanya lebih efisien menurut saya juga merupakan kesempatan dalam mengadakan rekruitmen politik agar memiliki kualifikasi pemimpinan"... (RADP, 2019)

Mahasiswa yang merupakan generasi Y (lahir 1977-1994) dan Z (lahir 1995-2012) memiliki asumsi bahwa Pemilu serentak merupakan praktik politik baru bagi bangsa indonesia. Menyikapi temuan ini, maka bekal yang dibutuhkan bagi 
Jurnal Pemikiran Sosiologi Volume 7 No.1 2020

Penggalangan Civic Literacy Melalui Organisasi Kemahasiswaan dan Pandangan mengenai Tantangan Demokrasi di Indonesia

Yayuk Hidayah, Sapriya, Cecep Darmawan, Elly Malihah

mereka adalah literasi mengingat kebiasaan generasi ini yang selalu ingin up to date. Hasil survei terhadap penggunaan social networking (SN) dalam Pilpres pada tahun 2008 dengan melibatkan lebih dari 3.500 anak berusia 18 hingga 24 tahun menghasilkan situs jejaring media sosial digunakan anak muda dalam memperoleh informasi yang dapat menambah wacana mereka tentang praktik demokrasi (Baumgartner \& Morris, 2009). Generasi Y merupakan generasi yang dekat dengan teknologi, dalam event Pemilu diperlukan literacy agar generasi ini tetap mempunyai integritas dan percaya terhadap proses politik yang terjadi melalui jalan politik ini. Pemilihan umum di Inggris pada tahun 2005 yang menghasilkan kemenangan bagi partai Buruh di House of Commons diestimasikan menunjukkan pengoperasian perilaku partai melalui strategi kampanye (Johnston, Rossiter, \& Pattie, 2006). Perilaku aktor politik yang seringkali mengadakan kampanye dengan massif secara tersirat menunjukan perlunya literasi yang tepat bagi generasi muda.

Dengan pertanyan yang sama, peneliti mengajukan pertanyaan pada JR mahasiswa Universitas Negeri Yogyakarta memberikan tanggapan,

“... pemilu serentak bagi saya merupakan langkah kemajuan dalam mendewasakan politik bagi bangsa Indonesia, namun demikian, sebagai geerasi muda terutama kami yang hidup dengan teknologi menurut saya dalam pemilu ini diperlukan kebijaksaan dalam penggunaan teknologi karena rentan terhadap konflik dalam komunikasi media..." (JR, 2019) 
Jurnal Pemikiran Sosiologi Volume 7 No.1 2020

Penggalangan Civic Literacy Melalui Organisasi Kemahasiswaan dan Pandangan mengenai Tantangan Demokrasi di Indonesia

Yayuk Hidayah, Sapriya, Cecep Darmawan, Elly Malihah

Indonesia Yogyakarta atau yang disebut dengan Lembaga Eksekutif Mahasiswa di lingkungan Universitas Islam Indonesia Yogyakarta. Ia menyatakan,

..." isu kekinian saya tidak terlalu mengetahui, namun saya sering berkumpul ngopi bersama teman-teman dan berujung pada pendiskusian masalah yang sedang happening ..." (IAP, 2019)

Terdapat banyak langgam bagi pemuda dalam mengolah dan mendapatkan informasi publik. Penelitian di Belanda dengan melibatkan 808 pemuda yang berusia 15-25 tahun mengivestigasi mengenai bagaimana kaum muda menggabungkan aktivitas sipil daring (online) dan luring (offline) dalam berpartisipasi. Penelitian itu menunjukkan bahwa kegiatan online dan offline digabungkan dalam aktivisme dan saling berbagi (Hirzalla \& Zoonen, 2010)

Pengetahuan mengenai isu kekinan kenegaraan akan berkolerasi pada cara pandang yang holistik terhadap persoalan yang terjadi. Penelitian yang mengeksplorasi persepsi dan pengetahuan tentang masalah lingkungan di tingkat lokal, nasional, dan global di kalangan mahasiswa Universitas Atatürk, Turki, menghasilkan korelasi antara kelompok siswa dan tingkat pengetahuan sesuai dengan usia dan jenis kelamin (Kulözü N. Environ Sci Pollut Res, 2016). Sementara itu, keterlibatan dalam komunitas dapat memberikan kontribusi terhadap pengetahuan sipil mereka. Hasil penelitian mengenai pengetahuan kewarganegaraan pada anak muda usia 16 hingga 25 tahun menunjukkan bahwa terdapat perbedaan pengetahuan pada remaja yang memiliki

keterlibatan dan tidak terlibat dalam komunitas (Hart, Atkins, Markey, \& Youniss, 2004).

Seterusnya peneliti mengajukan pertanyaan mengenai partisipasi politik era kini pada mahasiswa. Partisipan memberikan pendapat bahwa terjadi pergeseran dalam bentuk partisipasi politik. Partisipasi politik era kini merupakan era yang dekat dengan budaya digital (digitalisasi), sehingga dalam pelaksanaanya banyak melibatkan aspek teknologi informasi. Secara tidak langsung para partisipan memberikan pandangan mengenai tantangan demokrasi Indonesia di masa depan. LA mahasiswa Jurusan Pendidikan Agama Islam, Universitas Ahmad Dahlan misalnya menyatakan;

“...Partisipasi politik era kini menurut saya adalah sesuai dengan era kini yaitu era digital. Dan ini menjadi tantangan demokrasi Indonesia di masa depan..." (LA, 2019)

Civic literacy di era digital kini menghadirkan semacam tantangan demokrasi Indonesia di masa depan karena kehadiran media sosial yang menonjol. Dalam konteks budaya digital melalui teknologi informasi komunikasi (TIK) dan pengetahuan tentang melek kewarganegaraan, terdapat mediasi bentuk modal ekonomi, budaya dan sosial dalam membentuk keterlibatan individu (Selwyn, 2004). Masih dengan pertanyaan yang sama, Mahasiswa Universitas Atmajaya Yogyakarta yang terlibat dalam BEM menyatakan;

“...Partisipasi politik era kini menurut saya bermacam-macam walau keterlibatan saat Pemilu masih penting juga, namun saat ini terdapat banyak cara dalam menyampaikan aspirasi, Yang paling kentara saat ini tentu 
Jurnal Pemikiran Sosiologi Volume 7 No.1 2020

Penggalangan Civic Literacy Melalui Organisasi Kemahasiswaan dan Pandangan mengenai Tantangan Demokrasi di Indonesia

Yayuk Hidayah, Sapriya, Cecep Darmawan, Elly Malihah

banyak fenomena hashtag dan viral di manamana..." (SAS, 2019)

Senada dengan SAS, OTK mahasiswa Jurusan Komunikasi di Universitas Gadjah Mada Yogyakarta memberikan tanggapan,

“...Partisipasi politik era kini menurut saya lekat dengan digitalisasi. Dalam aspek politik tentu saja hal tersebut merupakan bentuk respon dan adaptasi terhadap perubahan..." (OTK, 2019)

Partisipan mempunyai pendapat bahwa tantangan demokrasi di masa depan bagi Indonesia adalah bagaimana wujud adaptasi terhadap teknologi informasi komunikasi dalam tataran kehidupan politik secara konkrit. Penelitian mengenai peran profesional kampanye dalam kampanye Pemilu di era digital secara keseluruhan menyimpulkan bahwa dibutuhkannya peran profesional kampanye sebagai wujud dalam mengisi kekosongan keterbatasan institusional partai politik dalam kampanye (Farrell, Kolodny, \& Medvic, 2001). Hadirnya teknologi informasi dan komunikasi dalam arena politik menghadirkan seruan dalam tantangan demokrasi Indonesia di masa depan. SI seorang mahasiswa dari Universitas Islam Negeri "Sunan Kalijaga" Yogayakarta menyatakan;

“...bagi kami, keterlibatan politik saat ini lebih banyak jalan. Era digital banyak tawaran dalam mengakses informasi, namun dalam menyaring informasi tentu saja masih memerlukan banyak arahan dan bimbingan dari berbagai pihak..." (SI, 2019)
Menghadapi tantangan demokrasi Indonesia di masa depan, Indonesia tetap sesuai dengan dengan cita-cita bangsa Indonesia seperti yang ada dalam pembukaan UUD 1945 alenia ke 4 (Saputri \& Bagus Edi Prayogo, 2018). Selain itu berkaitan dengan tantangan demokrasi Indonesia di masa depan, maka upaya untuk menjadikan Pancasila sebagai sumber literasi dalam kehidupan berbangsa menjadi penting adanya. Menginternalisasi nilainilai Pancasila adalah upaya dalam menciptakan kehidupan berbangsa dan bernegara dengan berdasarkan pada nilai-nilai Pancasila (Dianasari \& Hidayah, 2019)

Penggalangan civic literacy melalui organisasi kemahasiswaan dalam tantangan demokrasi Indonesia di masa depan adalah dalam rangka memelihara tanggungajawab kewarganegaraan dari mahasiswa. Melalui organisasi kemahasiswaan, diharapkan mahasiswa mampu bertindak demokratis, berfikir secara komperehensif dan kritis. Dalam skema reformasi kurikuler, literasi kewarganegaraan kini berada pada posisi yang sering berubah (Cortés, 1983). Tantangan demokrasi Indonesia di masa depan menempatkan warga negara Indonesia untuk dapat memiliki kesadaran dalam melaksanakan hak dan kewajiban serta dapat menerapkan prinsip-prinsip demokrasi. Menjadikan warga negara yang cerdas dan sadar mengenai hak kewajibanya dalam ruang lingkup kehidupan berbangsa dan bernegara menjadi pekerjaan rumah yang membutuhkan kerja sama dari berbagai pihak. Masalah-masalah dalam kehidupan berbangsa dan bernegara seperti demokrasi, Hak Asasi Manusia (HAM), dan aspek kebangsaan menjadi bagian yang harus sudah 
Jurnal Pemikiran Sosiologi Volume 7 No.1 2020

Penggalangan Civic Literacy Melalui Organisasi Kemahasiswaan dan Pandangan mengenai Tantangan Demokrasi di Indonesia

Yayuk Hidayah, Sapriya, Cecep Darmawan, Elly Malihah

bersifat familiar. Hubungan antara berkembangnya masyarakat demokratis dan berkembangnya pengetahuan adalah hubungan yang sudah lama dengan demikian maka sudah seharusnya upaya pencerdasan kewarganegaraan merangkul berbagai aspek dan berbagai ranah (Heiland \& Huber, 2015).

Adanya pengharapan terhadap pemimpin selanjutnya dari generasi muda adalah wujud dari keinginan adanya perubahan dari kondisi tertentu. Studi tentang kajian kewarganegaraan kepada lebih dari 11.000 siswa yang menulis surat kepada presiden berikutnya menjelang pemilihan di Amerika Serikat pada tahun 2016 menghasilkan setidaknya terdapat 43 topik yang menjadi pengharapan dari para siswa seperti antara lain, imigrasi, senjata, biaya sekolah (Garcia, Levinson, \& Gargroetzi, 2019). Civic literacy melalui organisasi kemahasiswaan menjadi alternatif dalam memperkenalkan mahasiswa agar menyentuh ranah politik yang berorientasi pada kepentingan publik. Hasil analisis survei nasional selama dua dekade di Amerika Serikat dan dua studi Euro barometer memunculkan pengharapan akan adanya replikasi ukuran dalam berbagai studi tentang pemahaman publik dan sikap terhadap sains dan teknologi (Miller, 1998).

Upaya menghidupkan atmosfir demokrasi telah terjadi di belahan dunia. Upaya mencerdaskan warga negara melalui sekolah juga dipercaya menjadi bagian dalam meningkatkan pengetahuan sipil. Sekolah Dasar Edwin M. Stanton di Philadelphia, Amerika Serikat misalnya, mengembankan kurikulum kewarganegaraan yang merupakan salah satu upaya untuk membangun pembelajaran kewarganegaraan dan upaya dalam menggambarkan bagaimana kewarganegaraan dapat menjadi saluran yang efektif untuk menghubungkan kurikulum dan praktik kepemimpinan (Brasof \& Spector, 2016). Sementara berkaitan dengan ideologi Pendidikan Kewarganegaraan, seorang guru berhubungan dengan bagaimana dan apa yang mereka ajarkan. Hasil studi menjelaskan bahwa guru yang konservatif dan liberal cenderung mendukung kurikulum berdasarkan lembaga sipil milik negara. Namun sebaliknya, guru dengan orientasi kritis kurang mendukung institusi negara dan lebih cenderung mendukung kurikulum berdasarkan institusi sosial (Knowles, 2018). Selanjutnya tentang keefektifan pendidikan kewarganegaraan di Amerika Serikat, hasil penelitian juga menunjukkan bahwa Pendidikan Kewarganegaraan yang memengaruhi kapasitas demokratis hanya berlaku untuk siswa yang berasal dari latar belakang tertentu, padahal metode pengajaran guru dapat mempengaruhi stimulasi pengetahuan bagi siswa (Gainous \& Martens, 2011).

Secara umum dalam pengajaran, adanya keterkaitan komponen dalam pencapaian tujuan pendidikan menjadi penunjang dalam keberhasilan tujuan pendidikan. Perlunya interaksi yang positif antar komponen pendidikan seperti evaluasi, sumber belajar, pedekatan, materi dan lain-lain menunjang dalam penciptaan hasil belajar yang efisien dan efektif. Di Amerika Serikat, sejak amandemen ke-10, konstitusi Amerika Serikat telah menjadikan pendidikan sebagai fungsi negara. Kesiapan lulusan sekolah menengah dan untuk jenjang selanjutnya (Pendidikan Tinggi) di mungkinkan tergantung pada negara tempat tinggal. 
Jurnal Pemikiran Sosiologi Volume 7 No.1 2020

Penggalangan Civic Literacy Melalui Organisasi Kemahasiswaan dan Pandangan mengenai Tantangan Demokrasi di Indonesia

Yayuk Hidayah, Sapriya, Cecep Darmawan, Elly Malihah

Salah satunya adalah 50 negara bagian dan District di Columbia sangat bervariasi dalam kebijakan dan praktik dalam pendidikan (Owings, Kaplan, Myran, \& Doyle, 2017). Sementara itu, efek "brain drain" atas fenomena banyaknya calon mahasiswa pascasarjana dari wilayah Afrika sub-Sahara yang terus memilih Amerika Serikat sebagai tujuan studi mereka untuk menempuh pendidikan tinggi (Smith, 2007) telah mengarah pada adanya pengaruh dari faktor pendidikan, metode dan pengajaran. Lebih lanjut era digital saat ini, munculnya kekuatiran adanya berita palsu (hoax) sehingga memunculkan kebutuhan atas pentingnya berbagai bentuk literasi media (Jones-Jang, Mortensen, \& Liu, 2019). Hasil penelitian yang telah dilakukan peneliti menunjukan bahwa terdapat pandangan yang positif terhadap Pemilu sebagai skema rekruitmen kepemimpinan politik yang sesuai dengan falsafah bangsa Indonesia.

Dengan demikian maka penggalangan civic literacy melalui organisasi kemahasiswaan dalam tantangan demokrasi Indonesia di masa depan diharapkan dapat menjadi solusi dan jawaban atas keresahan masa depan demokrasi Indonesia.

\section{E. Kesimpulan}

Berdasarkan hasil dan pembahasan penelitian, maka dapat disimpulkan bahwa terdapat cara pandang yang positif di kalangang mahasiswa mengenai pelaksanaan Pemilu secara serentak pada tahun 2019. Cara pandang yang cukup positif ini tersirat pada harapan adanya rekruitmen kepemimpinan politik yang sesuai dengan falsafah bangsa (Pancasilais). Dalam menyaring pengetahuan isu kenegaraan terkini terhimpun data bahwa terdapat beberapa cara dalam memperleh informasi termasuk keterlibatan mahasiswa dalam rangka partisipasi politik mereka, khususnya yang kental dengan nuansa digitalisasi.

Penggalangan civic literacy melalui organisasi kemahasiswaan dalam menghadapi tantangan demokrasi indonesia di masa depan menjadi solusi dalam menyeimbangkan pondasi pengetahuan masyarakat dalam rangka mengokohkan demokrasi sehingga tercipta smart and good citizen. Melalui organisasi kemahasiswaan dapat menjadi wadah bagi para mahasiswa dalam perwujudan praktik kewarganegaraan sehingga dapat menjadi dasar dari penguatan civic literacy dan good citizen.

Organisasi kemahasiswaan bagi mahasiswa menjadi solusi dalam pembelajaran peran sebagai warga negara. Mahasiswa selama ini dianggap sebagai bagian dari masyarakat yang mempunyai dominasi keilmuan yang dapat bermanfaat bagi kehidupan berbangsa dan bernegara. Oleh karena itu mereka sudah selayaknya dapat berperan dan berkontribusi aktif dalam kehidupan berbangsa dan bernegara dengan berlandaskan pada pengetahuan yang dimilikinya sehingga mandat sebagai agent social of change dapat terwujud. 
Jurnal Pemikiran Sosiologi Volume 7 No.1 2020

Penggalangan Civic Literacy Melalui Organisasi Kemahasiswaan dan Pandangan mengenai Tantangan Demokrasi di Indonesia

Yayuk Hidayah, Sapriya, Cecep Darmawan, Elly Malihah

\section{Daftar Pustaka}

Ardian, Y., \& Harmawati, Y. 2018. "Analisis penguasaan kompetensi kewarganegaraan pada mahasiswa PPKn Universitas PGRI Madiun." Jurnal Citizenship: Media Publikasi Pendidikan Pancasila dan Kewarganegaraan, 1(2): 76-83.

Baumgartner, J. C., \& Morris, J. S. 2009. “MyFaceTube Politics: Social Networking Web Sites and Political Engagement of Young Adults. “ Social Science Computer Review, 28(1): 2444.

DOI: https://doi.org/10.1177/08944393093343 25

Bogdan, T. S. J. 1993. Kualitatif: Dasar - Dasar Penelitian. Surabaya: Usaha Nasional.

Brasof, M., \& Spector, A. 2016. “Teach students about civics through schoolwide governance." Phi Delta Kappan, 97(7): 63-68. DOI: https://doi.org/10.1177/00317217166416 52

Cortés, C. E. 1983. "The Mass Media: Civic Education's Public Curriculum." Journal of Teacher Education, 34(6): 25-29. DOI: https://doi.org/10.1177/00224871830340 0608

Dianasari, \& Hidayah, Y. 2019. "Pancasila Sebagai Literasi Moral Pada Pendidikan Dasar Di Era Revolusi Industri 4.0." Prosiding Seminar Nasional Pendidikan I. Majalengka: Fakultas Keguruan dan Ilmu Pendidikan Universitas Majalengka.

Dudley, R. L., \& Gitelson, A. R. 2002. "Political Literacy, Civic Education, and Civic Engagement: A Return to Political Socialization?" Applied Developmental Science 6(4): 175-182. DOI: https://doi.org/10.1207/S1532480XADS06 04

Fachruddin, F. 2006. Agama dan Pendidikan Demokrasi: Pengalaman Muhammadiyah dan Nadhlatul Ulama. Banten: Pustaka Alvabet.

Farrell, D. M., Kolodny, R., \& Medvic, S. 2001. "Parties and Campaign Professionals in a Digital Age: Political Consultants in the United States and Their Counterparts Overseas." Harvard International Journal of Press/Politics, 6(4): 11-30.

DOI: https://doi.org/10.1177/10811800112917 2314

Gainous, J., \& Martens, A. M. 2011. “The Effectiveness of Civic Education: Are "Good" Teachers Actually Good for "All” Students?" American Politics Research, 40(2): 232-266. DOI: https://doi.org/10.1177/1532673X114194 92

Garcia, A., Levinson, A. M., \& Gargroetzi, E. C. 2019. "Dear Future President of the United States: Analyzing Youth Civic Writing Within the 2016 Letters to the Next President Project." American Educational Research Journal, $0002831219870129 . \quad$ DOI: https://doi.org/10.3102/00028312198701 29 
Jurnal Pemikiran Sosiologi Volume 7 No.1 2020

Penggalangan Civic Literacy Melalui Organisasi Kemahasiswaan dan Pandangan mengenai Tantangan Demokrasi di Indonesia

Yayuk Hidayah, Sapriya, Cecep Darmawan, Elly Malihah

Hart, D., Atkins, R., Markey, P., \& Youniss, J. 2004.

"Youth Bulges in Communities: The Effects of Age Structure on Adolescent Civic Knowledge and Civic Participation." Psychological Science, 15(9): 591-597. DOI: https://doi.org/10.1111/j.09567976.2004.00725.x

Heiland, D., \& Huber, M. T. 2015. "The Role of the Arts and Humanities in Civic Learning and Engagement: The US Debate." Arts and Humanities in Higher Education, 14(3): 231238.

DOI: https://doi.org/10.1177/14740222155839 45

Hidayah, Yayuk, Ulfah Nufikha, Suyitno, S. 2019. "Analisis Pendekatan Pembelajaran Mata Kuliah Wajib Umum Pancasila dan Pendidikan Kewarganegaraan Di Perguruan Tinggi." JPK (Jurnal Pancasila dan Kewarganegaraan), 4 (1): 22-33. DOI: https://doi.org/10.24269/jpk.v4.n1.2019.p p22-33

Hirzalla, F., \& Zoonen, L. van. 2010. "Beyond the Online/Offline Divide: How Youth's Online and Offline Civic Activities Converge." Social Science Computer Review, 29(4): 481-498. DOI:

https://doi.org/10.1177/08944393103855 38

Hylton, M. E. 2018. "The Role of Civic Literacy and Social Empathy on Rates of Civic Engagement Among University Students." Journal of Higher Education Outreach and Engagement, 22(1): 87-106.
Johnston, R., Rossiter, D., \& Pattie, C. 2006. "Disproportionality and Bias in the Results of the 2005 General Election in Great Britain: Evaluating the Electoral System's Impact." Journal of Elections, Public Opinion and Parties, 16(1): 37-54. DOI: https://doi.org/10.1080/13689880500505 157

Jones-Jang, S. M., Mortensen, T., \& Liu, J. 2019. “Does Media Literacy Help Identification of Fake News? Information Literacy Helps, but Other Literacies Don't." American Behavioral Scientist, $0002764219869406 . \quad$ DOI: https://doi.org/10.1177/00027642198694 06

Kansil, C. S. T., \& Kansil, C. S. T. 2011. Sistem Pemerintahan Indonesia, (Edisi Revisi). Jakarta: Bumi Aksara.

Keputusan Menteri Pendidikan Dan Kebudayaan Republik Indonesia Nomor 155 /U/1998 Tentang Pedoman Umum Organisasi Kemahasiswaan Di Perguruan Tinggi.

Knowles, R. T. 2018. "Ideology in the schools: Developing the teacher's Civic Education Ideology Scale within the United States." Education, Citizenship and Social Justice, 14(3): $\quad 260-278 . \quad$ DOI: https://doi.org/10.1177/17461979188006 64

Kulözü N. Environ Sci Pollut Res. 2016. "Youths' Perception and Knowledge towards Environmental Problems in a developing Country: the case of Atatürk University, 
Jurnal Pemikiran Sosiologi Volume 7 No.1 2020

Penggalangan Civic Literacy Melalui Organisasi Kemahasiswaan dan Pandangan mengenai Tantangan Demokrasi di Indonesia

Yayuk Hidayah, Sapriya, Cecep Darmawan, Elly Malihah

Turkey." Environmental Science and

Pollution Research, 23(12): 12482-12490.

DOI: https://doi.org/10.1007/s11356-0166693-22016

Leung, C.-H., \& Chan, H. Y. 2019. “Teaching Classics as Moral and Civic Education: The Impact of Core Curriculum at The Chinese University of Hong Kong." Asian Education and Development Studies, 8(2): 217-232. DOI: https://doi.org/10.1108/AEDS-03-20170023

Lin, A. R. 2014. "Examining Students' Perception of Classroom Openness as a Predictor of Civic Knowledge: A Cross-National Analysis of 38 Countries." Applied Developmental Science 18(1): 37-41. DOI: https://doi.org/10.1080/10888691.2014.8 64204

Miles, Mathew. B., \& Huberman, Michael. 1992. Analisis data Kualitatif. Jakarta: UI Press.

Miller, J. D. 1998. "The Measurement of Civic Scientific Literacy." Public Understanding of Science, 7(3): 203-223. DOI: https://doi.org/10.1088/0963$6625 / 7 / 3 / 001$

Milner, Henry. 2001. "Social Capital, Civic Literacy and Political Participation: Explaining Differences in Voter Turnout," dalam Dowding K., Hughes J., Margetts H. (eds). Challenges to Democracy. Political Studies Association Yearbook. London: Palgrave Macmillan.
Moleong, Lexy. J. 2007. Metodologi Penelitian Kualitatif. Bandung: PT Remaja Rosdakarya Offset.

Owings, W., Kaplan, L. S., Myran, S., \& Doyle, P. 2017. "How Variations in State Policies and Practices Impact Student Outcomes: What Principals and Professors Need to Know." NASSP Bulletin, 101(4): 299-314. DOI: https://doi.org/10.1177/01926365177455 82

Pollack Seth.S. 2015. "Critical Civic Literacy as an Essential Component of the Undergraduate Curriculum", dalam Jacob W.J., Sutin S.E., Weidman J.C., Yeager J.L. (eds) Community Engagement in Higher Education. Pittsburgh Studies In Comparative and International Education. Rotterdam: SensePublishers.

Prihatmoko, J. J. 2003. Pemilu 2004 dan Konsolidasi Demokrasi. Semarang: LP2I.

Putnam, Robert. D. 1995. “Bowling Alone: America's Declining Social Capital." Journal of Democracy Vol 6 (1): 65-78.

Raharjo, Armawi, A., \& Soerjo, D. 2017. "Penguatan Civic Literacy Dalam Pembentukan Warga Negara Yang Baik (Good Citizen) Dan Implikasinya Terhadap Ketahanan Pribadi Warga Negara Muda (Studi Tentang Peran Pemuda HMP PPKn Demokratia Pada Dusun Binaan." Jurnal Ketahanan Nasional Vol 23 (2): $\quad 51-74 . \quad$ DOI: https://doi.org/10.22146/jkn.26457

Rapeli Lauri. 2014. "Democratic Theory and Political Knowledge," dalam Rapeli, L, The Conception 
Jurnal Pemikiran Sosiologi Volume 7 No.1 2020

Penggalangan Civic Literacy Melalui Organisasi Kemahasiswaan dan Pandangan mengenai Tantangan Demokrasi di Indonesia

Yayuk Hidayah, Sapriya, Cecep Darmawan, Elly Malihah

of Citizen Knowledge in Democratic Theory:

The Theories, Concepts and Practices of

Democracy. London: Palgrave Pivot.

Saputri, W. D., \& Bagus Edi Prayogo. 2018.

"Tantangan Demokrasi di Era Globalisasi

Demi Mewujudkan Pencegahan Politik Uang dalam Pemilu." Seminar Nasional Hukum Universitas Negeri Semarang Volume 4 (3): 1191-1204.

Selwyn, Neil. 2004. "Reconsidering Political and Popular Understandings of the Digital Divide". New Media \& Society, 6 (3): 341362.

DOI: https://doi.org/10.1177/14614448040425 19

Smith, B. Q. 2007. “Globalization and Desire: A Case Study of International Graduate Student Education in Literacy Studies." Journal of Studies in International Education, 11(1): $54-72$. DOI: https://doi.org/10.1177/10283153052830 52

Soemantri. 2011. Pendidikan Kewarganegaraan. Bandung: Alfabeta.

Stambler, Leah. G. 2013. 14. Civic Literacy. New Haven: Yale University - the Pier Insitute.

Suryadi, K. 2010. Inovasi Nilai dan Fungsi Komunikasi Partai Politik bagi Penguatan Civic Literacy. Pidato Pengukuhan Guru Guru Besar Ilmu Komunikasi Politik Fakultas Pendidikan Ilmu Pengetahuan Sosial, UPI Bandung.
Tapia, A. H., \& Ortiz, J. A. 2010. “Network Hopes Municipalities Deploying Wireless Internet to Increase Civic Engagement." Social Science Computer Review, 28(1): 93-117. DOI: https://doi.org/10.1177/08944393093351 69

Torney-Purta, J. 2010. "The School's Role in Developing Civic Engagement: A Study of Adolescents in Twenty-Eight Countries." Applied Developmental Science, 6(4): 203212.

DOI: https://doi.org/10.1207/S1532480XADS06 04

Van Helvoort J. 2019. "Four Spaces of Civic Literacy Education: A Literature Review." Dalam Kurbanoğlu S. et al. (eds), Information Literacy in Everyday Life. ECIL 2018. Communications in Computer and Information Science, 989. DOI: https://doi.org/10.1007/978-3-03013472-3_9 